J. Lake Sci. (湖泊科学), 2015, 27(4): 643-648

DOI $10.18307 / 2015.0412$

(C) 2015 by Journal of Lake Sciences

\title{
城市河道黑臭底泥对挺水植物光合荧光特性的影响
}

\author{
欧 媛 ${ }^{1}$, 韩罙明 ${ }^{1}$, 李 强 $^{2}$, 王文林 ${ }^{1}$, 王国祥 ${ }^{1 * *}$ \\ ( 1 : 南京师范大学地理科学学院, 南京 210023) \\ ( 2 : 重庆文理学院水环境修复重点实验室, 重庆 402160)
}

摘 要: 城市河道黑臭现象日益严重, 探讨常见湿地植物在黑臭底泥中的生长, 有利于为河道修复物种选择提供科学依 据. 研究黑臭底泥对 3 种常见湿地植物——菖蒲 (Acorus calamus)、美人蕉 (Canna indica) 及慈姑 (Sagittaria sagittifolia) 生 长状况和叶片叶绿素苂光参数的影响. 结果表明: 菖蒲和美人蕉在第 $30 \sim 40 \mathrm{~d}$ 时生物量增量明显降低, 慈姑的生物量增 量在整个实验中持续增加; 通过比较 3 种湿地植物的苂光参数可知, 菖蒲和美人蕉的光化学淬灭系数 $(q P)$ 、相对光合电 子传递速率 $(r E T R)$ 值在第 $10 \mathrm{~d}$ 时达到最大, 分别为 $41.33 \mu \mathrm{mol} /\left(\mathrm{m}^{2} \cdot \mathrm{s}\right)$ 和 $68.60 \mu \mathrm{mol} /\left(\mathrm{m}^{2} \cdot \mathrm{s}\right)$, 后 $30 \mathrm{~d}$ 一直下降; 慈姑 $q P 、 r E T R$ 值在第 $30 \mathrm{~d}$ 时增加; 在第 $40 \mathrm{~d}$ 时, 美人蕉 $q P$ 值下降, 非光化学淬灭系数 $(q N)$ 值上升, 叶片有较强的热耗散能力, 而菖蒲的 $q P 、 q N$ 值同时下降, 黑臭底泥对菖蒲叶片的光合系统 PS II 造成伤害. 这说明黑臭底泥对菖蒲和美人蕉的光合能 力产生较长期抑制, 而慈姑可较快适应黑臭底泥的胁迫. 因此利用湿地植物修复黑臭河道时, 可优先选择慈姑, 其次是美 人蕉, 最后是菖蒲.

关键词 : 菖蒲;美人蕉;慈姑;黑臭底泥;光合特性

\section{Impact of black odor sediment on photosynthetic fluorescence of three emergent plant species}

OU Yuan ${ }^{1}$, HAN Ruiming ${ }^{1}$, LI Qiang ${ }^{2}$, WANG Wenlin ${ }^{1} \&$ WANG Guoxiang ${ }^{1}$

(1: College of Geographical Science, Nanjing Normal University, Nanjing 210023, P. R. China)

(2: Key Laboratory of Water Environmental Restoration, Chongqing University of Arts and Sciences, Chongqing 402160, P. R. China)

\begin{abstract}
Black odor urban rivers raised increasing concerns on its subsequent serious pollution. Investigation over the impact of black odorous sediment on the growth of wetland plants can offer scientific basis for species selection for river remediation. Acorus calamus, Canna indica and Sagittaria sagittifolia were cultivated in black odorous sediment to determine growth parameters including the change of shoot biomass, and photosynthetic fluorescence parameters including $F_{\mathrm{v}} / F_{\mathrm{m}}$, Yield, $q P, q N, r E T R$ of leaves. The results showed that after 40 days, the black odorous sediment had decreased shoot biomass of $A$. calamus, C. indica compared to that of day 30, while $S$. sagittifolia increased; Values of $q P, r E T R$ in A. calamus and C. indica reached to the maximum of $41.33 \mu \mathrm{mol} /\left(\mathrm{m}^{2} \cdot \mathrm{s}\right)$ and $68.60 \mu \mathrm{mol} /\left(\mathrm{m}^{2} \cdot \mathrm{s}\right)$ at day 10 , then decreased continuously till the end of the experiment. However, values of $q P, r E T R$ in $S$. sagittifolia peaked at day 10 , then declined and increased after day 30 till the end of the experiment. It showed that black odorous sediment restrained the photosynthetic fluorescence of $A$. calamus and $C$. indica, whereas $S$. sagittifolia could adapt to the stress condition in less than 40 days; at day $40, q P$ of $C$. indica decreased and $q N$ increased, illustrating that the leaf of $C$. indica had relatively higher capacity of heat dissipation, while the decline of $q P, q N$ in $A$. calamus suggested that black odorous sediment damaged the photosynthetic system of $A$. calamus. In conclusion, when using wetland plants to remediate black odor river, the first choice is $S$. sagittifolia, then $C$. indica and the last A. calamus.
\end{abstract}

Keywords: Acorus calamus; Canna indica; Sagittaria sagittifolia; black odorous sediment; photosynthetic fluorescence

* 国家水体污染控制与治理科技重大专项 (2012ZX07101-008-02) 和重庆市基础与前沿研究计划项目 ( cstc2013jcyjA20024) 联合资助. 2014-08 - 11 收稿;2014-12-18 收修改稿. 欧媛 (1988 ), 女, 硕士研究生; E-mail : ouyuan1010@163.com.

** 通信作者;E-mail : wangguoxiang@ njnu. edu.cn. 
近年来, 由于人类活动加剧, 城市河道黑臭现象日益严重 ${ }^{[1-2]}$, 利用植物生态修复已成为许多城市水环 境治理的重要方法,已被越来越多人所认可 ${ }^{[3-5]}$, 而水生植物能在黑臭河道中生长是利用植物生态修复的基 础和前提. 富营养化水体对水生植物的影响, 多集中在高营养盐浓度胁迫沉水植物的生理生化 ${ }^{[6-11]}$, 水生植 物对沉积物底泥氮磷、有机质的吸附方面 ${ }^{[12-16]}$. 关于底质负荷对水生植物生长影响的研究较少, 尤其是黑臭 河道底泥对湿地植物生长的影响. 目前黑臭河道的修复多运用湿地植物, 所以研究黑臭河道底泥对湿地植 物生长的影响具有重要意义.

菖蒲 (Acorus calamus)、美人蕉 (Canna indica) 和慈姑 (Sagittaria sagittifolia) 为多年生湿地植物, 根系发 达, 对不利环境有较强的适应能力, 吸附能力强, 属河道修复常见植物 ${ }^{[17]}$. 本实验以城市黑臭河道底泥和慈 姑、菖蒲、美人蕉 3 种湿地植物构建实验系统, 室内模拟 3 种湿地植物在黑臭底泥中的生长情况, 探讨湿地植 物的生长及光合响应机制, 为黑臭河道修复的物种选择提供科学依据.

\section{1 材料与方法}

\section{1 底泥}

底泥采自某富营养化城市黑臭河道, 含水量为 $69.71 \%$, 氧化还原电位为 $-102.38 \mathrm{mV}, \mathrm{pH}$ 为 7.08 , 总有 机质、总氮、总磷含量分别为 19423. 57、1140.43、530. $15 \mathrm{mg} / \mathrm{kg}$. 采用彼得森采泥器于 2013 年 5 月采集表层 沉积物. 低温风干后过 100 目篮, 去除粗粒及动植物残体,充分混匀备用.

\section{2 湿地植物培养}

本实验选用典型湿地植物菖蒲 (A. calamus)、美人蕉 ( C. indica) 和慈姑 (S. sagittifolia). 2013 年 5 月将 从富营养河道采集的 3 种湿地植物种植在高密度聚乙烯柱内 (直径 $\times$ 高: $70 \mathrm{~mm} \times 35 \mathrm{~cm}$, 预先经过 $5 \%$ 的 $\mathrm{HCl}$ 处理后用蒸馏水冲洗干净), 底泥厚度为 $30 \mathrm{~cm}$, 每个柱子种植 1 株植物, 自然光照下生长 2 周. 实验开始 时 3 种植物的株高分别为 $11.9 \pm 0.9 、 10.2 \pm 0.7 、 9.8 \pm 0.6 \mathrm{~cm}$, 生物量分别为: $0.44 \pm 0.07 、 0.99 \pm 0.08$ 、 $0.50 \pm 0.12 \mathrm{~g}$.

\section{3 实验系统的构建}

实验系统的构建: 植物聚乙烯柱置于高密度聚乙烯桶底部 (顶直径 $\times$ 底直径 $\times$ 高: $100 \mathrm{~cm} \times 55 \mathrm{~cm} \times$ $95 \mathrm{~cm}$ ), 缓慢注人经阳光暴晒 $3 \mathrm{~d}$ 后的自来水, 淹水深度为 $3 \mathrm{~cm}$. 实验在玻璃温室内进行, 期间的平均温度为 $30 \pm 1.5^{\circ} \mathrm{C}$, 平均光照为 $(1000 \pm 325) \times 10^{2} \mathrm{~lx}$. 实验开始于 2013 年 6 月 9 日, 分别在第 $0 、 10 、 20 、 30 、 40 \mathrm{~d}$ 测定 菖蒲、美人蕉、慈姑的生物量, 同步测定其叶绿素苂光参数.

\section{4 叶绿素荧光参数测定}

实验第 $0 、 10 、 20 、 30 、 40 \mathrm{~d}$ 利用水下饱和脉冲调制 (DIVING-PAM, 德国 WALZ 公司) 和数据采集软件 Wincontrol 于 7:00 测定叶绿素苂光参数值, 随机选择 3 株顶部伸展叶片, 连体适应 $15 \mathrm{~min}$ 后, 打开叶夹, 开 启测量光 $\left(0.5 \mu \mathrm{mol} /\left(\mathrm{m}^{2} \cdot \mathrm{s}\right)\right.$ ) 得到 $F_{0}$ (暗适应样品的最小荧光产量), 再开启饱和脉冲光 (4000 $\mu \mathrm{mol} /$ $\left(\mathrm{m}^{2} \cdot \mathrm{s}\right), 0.8 \mathrm{~s}$ ) 测得 $F_{\mathrm{m}}$ (暗适应样品的最大苂光产量), 然后开启光强度为 $30 \mu \mathrm{mol} /\left(\mathrm{m}^{2} \cdot \mathrm{s}\right)$ 的光化光, 照 射叶片 $10 \mathrm{~s}$ 后, 再开启饱和脉冲光测得 $F_{\mathrm{m}}^{\prime}$ (光适应样品打开饱和脉冲时的最大苂光产量) 与 $F_{t}$ (任一给定时 间的苂光产量). $F_{\mathrm{v}} / F_{\mathrm{m}}$ ( 反映在合适条件下经过暗适应后 PS II 的最大量子产量) $=\left(F_{\mathrm{m}}-F_{0}\right) / F_{\mathrm{m}}{ }^{[18]}$, 光化 学淬灭系数 $q P=\left(F_{\mathrm{m}}^{\prime}-F_{t}\right) /\left(F_{\mathrm{m}}^{\prime}-F_{0}\right)$, 非光化学淬灭系数 $q N=\left(F_{\mathrm{m}}-F_{\mathrm{m}}^{\prime}\right) /\left(F_{\mathrm{m}}-F_{0}\right)$.

\section{5 快速光响应曲线测定}

实验第 $0 、 10 、 20 、 30 、 40 d$ 时, 测定叶片快速光响应曲线. 测定于早晨 7:00-8:00 进行. 随机选择 3 株顶 部伸展叶片测定快速光响应曲线 ${ }^{[19]}$. 分别绘出相对光合电子传递速率 $(r E T R)$ 与光强的快速光响应曲 线 ${ }^{[20]} . r E T R=0.84 \times 0.5 \times$ 光强 $\cdot\left(F_{\mathrm{m}}^{\prime}-F_{t}\right) / F_{\mathrm{m}}{ }^{[21]}$.

\section{6 数据分析}

采用 SPSS 16.0 软件对数据进行处理和分析, 实验期间对菖蒲植株生长的影响采用单因素方差分析 (ANOVA-I), 由 SigmaPlot 12.0 软件绘图.

\section{2 结果与分析}

\section{1 黑臭底泥对 3 种湿地植物生物量增量的影响}

植物生长过程中, 生物量增量作为植物光合作用净生产力, 用于比较不同植物的光合能力. 实验期间菖 
蒲、美人蕉的生物量增量表现为降低一升高降低的趋势, 而慈姑则持续增加 (表 1). 菖 蒲、美人蕉在第 $10 \sim 20 \mathrm{~d}$ 生物量增量明显下 降, 仅分别为第 $0 \sim 10 \mathrm{~d}$ 的 $45.7 \% 、 72.4 \%$, 菖蒲、美人蕉在第 $30 \sim 40 \mathrm{~d}$ 生物量增量也下 降, 仅分别为第 $20 \sim 30 \mathrm{~d}$ 的 $40.6 \% 、 30.4 \%$ $(P<0.05)$, 说明菖蒲和美人蕉的光合作用 净生产力下降. 而慈姑生物量增量明显增加 $(P<0.05)$, 说明实验期间慈姑的光合能力 一直增大. 在实验前 $30 \mathrm{~d}, 3$ 种湿地植物生物 量增量表现为美人蕉 $>$ 慈姑 $>$ 菖蒲, 说明短 时间生长在黑臭底泥中, 美人蕉的光合作用
表 1 实验期间 3 种湿地植物生物量增量的变化*

Tab. 1 The changes of shoot biomass of of three wetland plants during the experiment period

\begin{tabular}{cccc}
\hline \multirow{2}{*}{ 时间 } & \multicolumn{3}{c}{ 生物量增量 $/ g$} \\
\cline { 2 - 4 } & 菖蒲 & 美人蕉 & 慈姑 \\
\hline $0 \sim 10 \mathrm{~d}$ & $0.35 \pm 0.04^{\mathrm{b}}$ & $1.09 \pm 0.13^{\mathrm{b}}$ & $0.38 \pm 0.16^{\mathrm{a}}$ \\
$10 \sim 20 \mathrm{~d}$ & $0.16 \pm 0.02^{\mathrm{a}}$ & $0.79 \pm 0.04^{\mathrm{a}}$ & $0.74 \pm 0.17^{\mathrm{b}}$ \\
$20 \sim 30 \mathrm{~d}$ & $0.96 \pm 0.11^{\mathrm{d}}$ & $2.10 \pm 0.37^{\mathrm{c}}$ & $1.22 \pm 0.41^{\mathrm{c}}$ \\
$30 \sim 40 \mathrm{~d}$ & $0.39 \pm 0.10^{\mathrm{c}}$ & $0.64 \pm 0.21^{\mathrm{a}}$ & $1.84 \pm 0.22^{\mathrm{d}}$ \\
\hline
\end{tabular}

* 同一列标注不同字母表示差异显著 $(P<0.05)$. 能力最强, 菖蒲最差; 随着时间的延长, 菖蒲和美人蕉的生物量增量减少, 光合能力下降, 到实验结束时生物 量增量表现为慈姑 $>$ 美人蕉 $>$ 菖蒲 $(P<0.05)$, 说明较短时间 $(\leqslant 30 \mathrm{~d})$ 美人蕉的光合作用净生产力最大, 在 较长时间 $(\geqslant 30 \mathrm{~d})$ 慈姑的光合能力最强, 而菖蒲的光合作用净生产能力最弱.

\section{2 黑臭底泥对 3 种湿地植物叶绿素荧光的影响}

叶绿素苂光参数是评估 PS II 状态的指标. 菖蒲、美人蕉和慈姑叶片最大光量子产量 $\left(F_{\mathrm{v}} / F_{\mathrm{m}}\right)$ 反映了当 所有光合系统 II (PS II ) 反应中心均处于开放态时的量子产量 ${ }^{[22]}$, 其值降低是受抑制最明显的特征之一 ${ }^{[23]}$. 3 种湿地植物的 $F_{\mathrm{v}} / F_{\mathrm{m}}$ 呈先上升后降低的趋势 (图 1 ), 第 $30 \mathrm{~d}$ 时, 菖蒲、美人蕉的 $F_{\mathrm{v}} / F_{\mathrm{m}}$ 值达到最大, 分别为 $0.787 、 0.798$, 后下降,而慈姑 $F_{\mathrm{v}} / F_{\mathrm{m}}$ 持续增加. 实验 $0 \sim 30 \mathrm{~d}$ 内美人蕉的 $F_{\mathrm{v}} / F_{\mathrm{m}}$ 大于慈姑,在第 $40 \mathrm{~d}$ 时, 美人 蕉的 $F_{\mathrm{v}} / F_{\mathrm{m}}$ 降低小于慈姑的 $F_{\mathrm{v}} / F_{\mathrm{m}}$ 值, 在整个实验期间菖蒲的 $F_{\mathrm{v}} / F_{\mathrm{m}}$ 值最小.

有效苂光产量 (Yield) 表示在照光下 PS II 的实际光化学效率, 反映植物吸收的光子供给 PS II 反应中心 的效率. Yield 变化趋势与 $F_{v} / F_{\mathrm{m}}$ 类似, 实验期间 3 种湿地植物 Yield 值都呈先升高后降低的趋势 (图 1 ), 第 $40 \mathrm{~d}$ 时 3 种湿地植物的 Yield 值降低,表明黑臭底泥对 3 种湿地植物的实际光化学效率有抑制作用; 实验期 间 3 种湿地植物的 Yield 值表现为前 $10 \mathrm{~d}$ 较接近,表明黑臭底泥短期胁迫对实际光化学效率的抑制作用不 大,第 $40 \mathrm{~d}$ 时,美人蕉的 Yield 值明显下降 $(P<0.05)$, 小于慈姑和菖蒲的值, 表明较长时间黑臭底泥的胁迫 对 3 种湿地植物的抑制效果不同,且对美人蕉的实际光化学效率的抑制作用最大.

光化学淬灭系数 $(q P)$ 是 PS II 天线色素吸收的光能用于光化学电子传递的份额, $q P$ 降低反映 PS II 中开 放中心比例和参与 $\mathrm{CO}_{2}$ 固定的电子减少. 菖蒲、美人蕉的 $q P$ 值呈先上升后降低的趋势 (图 1), 且在第 $10 \mathrm{~d}$ 达到最大值, 分别为 $0.29 、 0.59$, 差异显著 $(P<0.05)$, 后 $30 \mathrm{~d}$ 逐渐降低, 直到实验结束, 说明黑臭底泥对菖 蒲和美人蕉光化学反应的电子数有明显的胁迫影响. 慈姑的 $q P$ 值呈先上升后下降再上升的趋势, 在第 $40 \mathrm{~d}$ 时, 慈姑的 $q P$ 值显著上升 $(P<0.05)$, 说明慈姑可以适应黑臭底泥的胁迫作用. 3 种湿地植物的 $q P$ 值表现 为美人蕉 $>$ 慈姑 $>$ 菖蒲 $(P<0.05)$, 说明美人蕉 PS II 中开放中心比例和参与 $\mathrm{CO}_{2}$ 固定的电子最多.

$q N$ 反映天线色素吸收的光能不能用于电子传递而以热的形式耗散掉的光能部分, 是植物保护 PS II 的 重要机制. 3 种湿地植物的 $q N$ 值表现为美人蕉 $>$ 慈姑 $>$ 菖蒲 (图 1), 且差异显著 $(P<0.05)$, 表明美人蕉的 热耗散能力最强. 菖蒲和慈姑在第 $40 \mathrm{~d}$ 时呈下降趋势, 说明随着黑臭底泥的胁迫使菖蒲和慈姑的热耗散能 力减弱, 而美人蕉在第 $40 \mathrm{~d}$ 时 $q N$ 值上升至 0.810 , 说明美人蕉光合系统 PS II 将吸收过剩的能量通过热耗散 的形式释放,以保护自身组织免受过剩光的损害,体现美人蕉在黑臭底泥中生长的自我保护机制.

快速光响应曲线:PSI的 $r E T R$ 反映实际光强下的表观电子传递速率, $r E T R$ 用于度量光化学反应导致碳固 定的电子传递情况. 3 种湿地植物的 ETR 值表现为先增加、后降低的趋势 (图 2), 在第 $10 \mathrm{~d}$ 时达到最大, 饱和 光强都为 $690 \mu \mathrm{mol} /\left(\mathrm{m}^{2} \cdot \mathrm{s}\right)$, 但 $r E T R_{\text {max }}$ 则呈显著差异 $(P<0.05)$, 其中慈姑 $r E T R_{\text {max }}$ 为 $99.87 \mu \mathrm{mol} /\left(\mathrm{m}^{2} \cdot \mathrm{s}\right)$, 显著高于菖蒲 $\left(41.33 \mu \mathrm{mol} /\left(\mathrm{m}^{2} \cdot \mathrm{s}\right)\right)$ 和美人蕉 $\left(68.60 \mu \mathrm{mol} /\left(\mathrm{m}^{2} \cdot \mathrm{s}\right)\right)$. 菖蒲和美人蕉的 $E T R$ 值在后 $30 \mathrm{~d}$ 一 直下降, 说明黑臭底泥对菖蒲、美人蕉的光响应能力产生影响, 直到实验结束都没有恢复. 而慈姑 ETR 值于 第 $30 \mathrm{~d}$ 开始上升, 说明慈姑可以适应黑臭底泥对光相应能力的胁迫. 

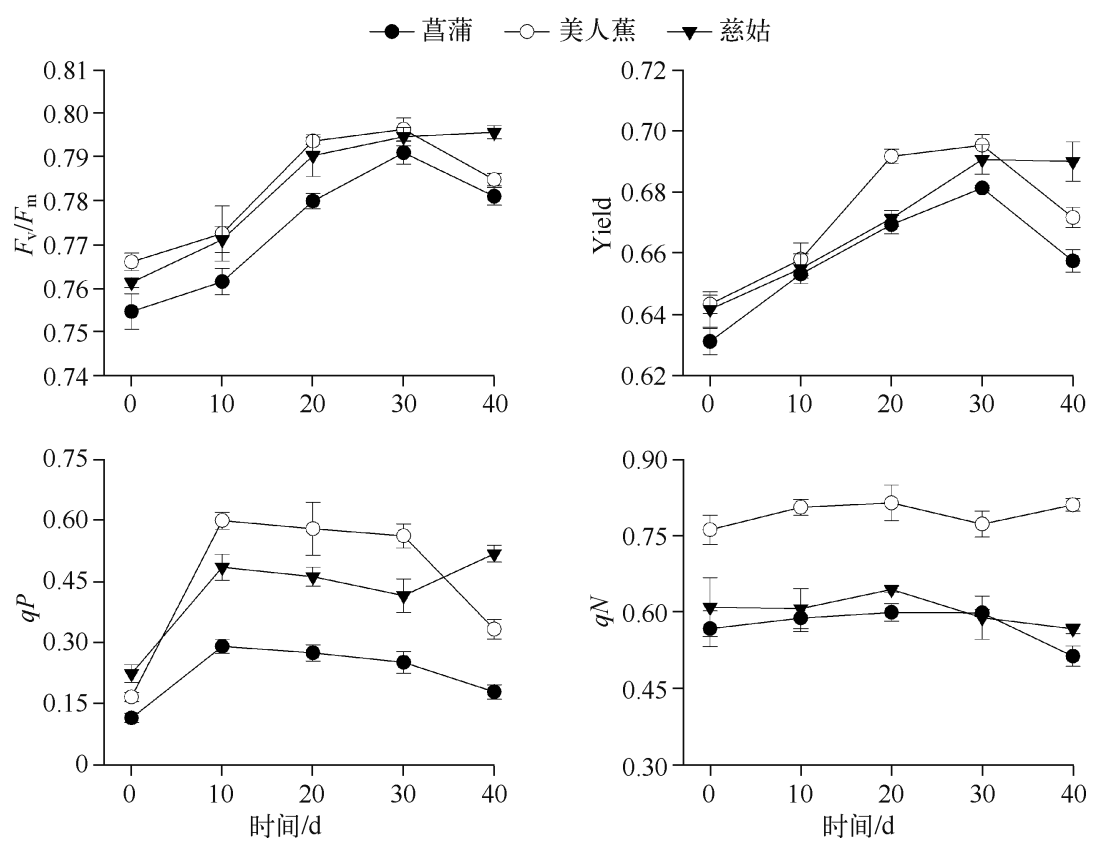

图 1 实验期间 3 种湿地植物 $F_{\mathrm{v}} / F_{\mathrm{m}} 、$ Yield $、 q P 、 q N$ 的变化

Fig. 1 Changes of $F_{\mathrm{v}} / F_{\mathrm{m}}$, Yield, $q P, q N$ of three wetland plants during the experiment period

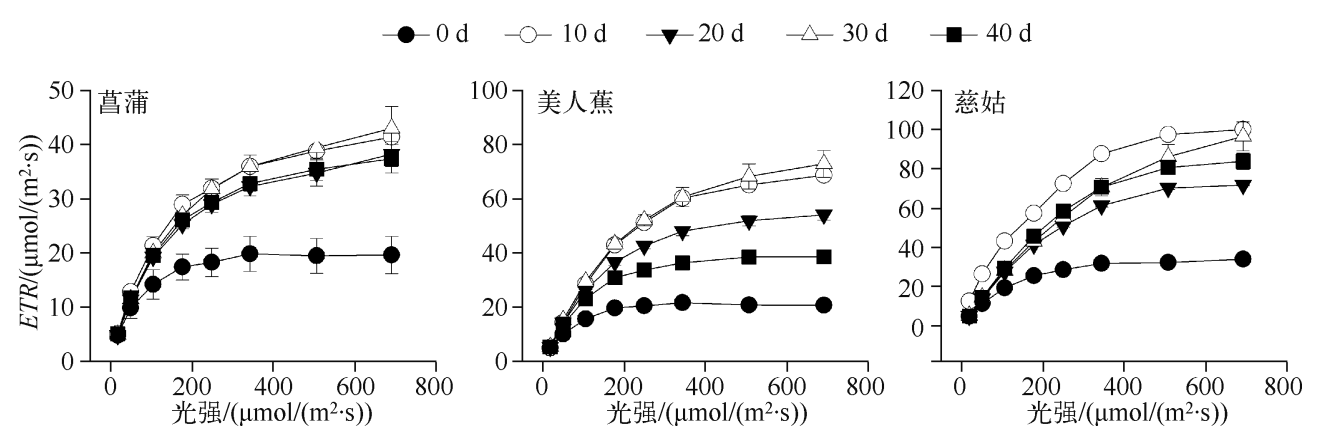

图 2 实验期间 3 种湿地植物的快速光响应曲线

Fig. 2 Rapid light curves of three wetland plants during the experiment period

\section{3 讨论}

\section{1 黑臭底泥对 3 种湿地植物生长的影响}

在实验开始的 $0 \sim 30 \mathrm{~d}$ 内, 生物量增量表现为美人蕉 > 慈姑 > 菖蒲, 在第 $30 \sim 40 \mathrm{~d}$ 时, 菖蒲和美人蕉的 生物量增量明显降低, 而慈姑持续增加, 最终 3 种湿地植物的生物量增量表现为慈姑 $>$ 美人蕉 $>$ 菖蒲. 这有 可能是由于菖蒲和美人蕉受到黑臭底泥的抑制或者是进人平稳的生长期,但 $F_{\mathrm{v}} / F_{\mathrm{m}}$ 的值在第 $30 \sim 40 \mathrm{~d}$ 时都 明显下降, 表明植物叶片受到了外界因子的抑制, 外界胁迫可能对 PS II 反应中心造成一定损伤, 说明美人蕉 和菖蒲受到抑制, 有研究表明较高的氮磷浓度对水生植物产生胁迫, 影响植物的正常生理活动, 抑制植物的 正常生长 ${ }^{[11,24]}$. 虽然慈姑的 $F_{\mathrm{v}} / F_{\mathrm{m}}$ 值在第 $30 \sim 40 \mathrm{~d}$ 时也稍有下降趋势, 但慈姑的生物量增量在第 $30 \sim 40 \mathrm{~d}$ 时显著增加 $(P<0.05)$, 说明慈姑可以适应黑臭底泥的外界胁迫. 


\section{2 黑臭底泥对 3 种湿地植物叶片光合机能的影响}

黑臭底泥对湿地植物生长的影响直接体现在其对光合作用的影响上. 叶片叶绿素苂光与光合作用中各 种反应过程密切相关, 任何环境因子对光合作用的影响可以通过叶片的叶绿素苂光动力学反映出来 ${ }^{[25]}$. PS II 系统的光化学效率是表征光化学反应状况的一个重要参数. 菖蒲、美人蕉和慈姑在黑臭底泥中的叶绿 素荧光参数表现出显著的差异, 3 种湿地植物 $F_{\mathrm{v}} / F_{\mathrm{m}}$ 、Yield 值在实验第 $30 \mathrm{~d}$ 达到最大后开始下降, 非胁迫条 件下该参数的变化极小,多数高等植物 $F_{\mathrm{v}} / F_{\mathrm{m}}$ 值在胁迫条件下明显下降 ${ }^{[26-27]}$, 当 $F_{\mathrm{v}} / F_{\mathrm{m}}$ 值低于 0.8 时,外界 胁迫可能对 PS II 反应中心造成一定损伤 ${ }^{[28]}$, 表明 3 种湿地植物都受到了胁迫. 再结合植物生物量增量的变 化, 菖蒲和美人蕉生物量增量在第 $30 \mathrm{~d}$ 明显下降, 慈姑的生物量增量在第 $30 \mathrm{~d}$ 显著增加 $(P<0.05)$, 说明 3 种湿地植物受到的胁迫程度不同. 3 种湿地植物的 $q P 、 r E T R$ 值均表现为慈姑 $>$ 美人蕉 $>$ 菖蒲, 说明慈姑吸收 的能量更多地参与了光化学反应, 电子传递速率增大, 合成更多的光合产物. 而在黑臭底泥中美人蕉和菖蒲 的吸收的光子供给 PS II 反应中心的效率将降低, 吸收的光能不能全部用于光合作用, 导致光合作用下降. $q N$ 值表现为美人蕉 $>$ 慈姑 $>$ 菖蒲, 美人蕉与菖蒲、慈姑存在显著差异 $(P<0.05)$, 表明美人蕉光合系统 PS II 将 吸收过剩的能量通过热耗散的形式释放, 以保护自身组织免受过剩光的损害,体现美人蕉在黑臭底泥中生 长的自我保护机制.

从时间上看, 菖蒲的 $q P 、 r E T R$ 值在第 $10 \mathrm{~d}$ 时达到极大值, 后 $30 \mathrm{~d}$ 一直下降至实验结束, 且菖蒲的 $q N$ 值 也下降, 说明菖蒲的 PS II 系统在黑臭底泥的胁迫下已经受到损伤, 热耗散能力不能增加, 再结合菖蒲的生物 量增量在第 $30 \sim 40 \mathrm{~d}$ 时明显下降 $(P<0.05)$, 说明黑臭底泥的胁迫影响菖蒲的光合作用能力, 植物根系也 出现少许腐烂的现象. 虽然美人蕉的 $q P 、 r E T R$ 值在实验后 $30 \mathrm{~d}$ 也下降, 但在第 $40 \mathrm{~d}$ 时, 美人蕉的 $q N$ 值上 升, 说明美人蕉仍有较高的热耗散能力, 可以保护 PS II 系统免受黑臭底泥的损伤. 慈姑 $q P 、 r E T R$ 值在第 $10 \mathrm{~d}$ 达到极大值, 在 $20 \mathrm{~d}$ 时出现下降, 说明黑臭底泥对慈姑的生长产生了胁迫, 而在第 $30 \mathrm{~d}$ 时 $q P 、 r E T R$ 值又上 升, 且生物量增量持续显著增加 $(P<0.05)$, 表明在黑臭底泥中慈姑更能有效地利用吸收的光能,合成生长 所需的物质, 说明慈姑可以较快地适应黑臭底泥的胁迫.

\section{4 结论}

1) 菖蒲、美人蕉的生物量增量在第 $30 \sim 40 \mathrm{~d}$ 时明显下降, $F_{\mathrm{v}} / F_{\mathrm{m}}$ 、Yield 值在第 $30 \sim 40 \mathrm{~d}$ 时出现下降, 表 明生长在黑臭底泥中的菖蒲和美人蕉受到抑制, 而慈姑的生物量增量在第 $30 \sim 40 \mathrm{~d}$ 显著增加, 说明慈姑可 以适应黑臭底泥的胁迫.

2) 在第 $40 \mathrm{~d}$ 时,菖蒲 $q P 、 q N$ 值同时下降,说明菖蒲的 PS II 系统在黑臭底泥的胁迫下已经受到损伤, 热 耗散能力不能增加; 美人蕉的 $q P$ 下降, 而 $q N$ 上升, 说明美人蕉仍有较高的热耗散能力, 可以保护 PS II 系统 免受黑臭底泥的伤害; 慈姑的 $q P$ 值上升, $q N$ 下降,说明黑臭底泥中生长的慈姑更能有效地利用光能合成生 长所需的物质, 说明慈姑可以适应黑臭底泥的胁迫. 因此在运用湿地植物修复黑臭河道时, 选种可以优先考 虑慈姑, 其次是美人蕉, 最后是菖蒲.

\section{5 参考文献}

[ 1 ] Kim LH, Choi E, Stenstrom MK. Sediment characteristics, phosphorus types and phosphorus release rates between river and lake sediments. Chemosphere, 2003, 50(1):53-61.

[2] 方宇趐,表祖楠. 城市河流中黑臭现象的研究. 中国环境科学,1993,13(4):256-262.

[ 3 ] 金相灿,屠清瑛. 湖泊富营养化调查规范. 北京: 中国环境科学出版社, 1990.

[ 4 ] 刘淑媛,任久长,由文辉. 利用人工基质无土栽培经济植物净化富营养化水体的研究. 北京大学学报: 自然科学版, 1999,35 (4):518-522.

[ 5 ] 杨丹菁,靖元孝, 陈兆平等. 水翁对富营养化水体氮,磷去除效果及规律研究. 环境科学学报, 2001, 21 (5): 637-639.

[ 6 ] Fang YY, Babourina O, Rengel Z et al. Spatial distribution of ammonium and nitrate fluxes along roots of wetland plants. Plant Science, 2007, 173(2) :240-246.

[ 7 ] Mony C, Koschnick TJ, Haller WT et al. Competition between two invasive Hydrocharitaceae(Hydrilla verticillata (L. f. ) 
(Royle) and Egeria densa(Planch)) as influenced by sediment fertility and season. Aquatic Botany, 2007, 86(3) :236242.

[ 8 ] Shearer JF, Grodowitz MJ, McFarland DG. Nutritional quality of Hydrilla verticillata ( L. f. ) Royle and its effects on a fungal pathogen Mycoleptodiscus terrestris (Gerd. ) Ostazeski. Biological Control, 2007, 41(2) :175-183.

[ 9 ] Xiao Y, Wang YL, Gao SX et al. Chemical composition of Hydrilla verticillata ( L. f. ) Royle in Taihu Lake. Chinese Journal of Chemistry, 2007, 25(5):661-665.

[10] 刘 燕,王圣瑞, 金相灿等. 水体营养水平对 3 种沉水植物生长及抗氧化酶活性的影响. 生态环境学报,2009,18 (1) :57-63.

[11］王 瑁,顾宇飞,朱增银. 不同营养状态下金鱼藻的生理响应. 应用生态学报,2005,16(2) :337-340.

[12] 李振国, 王国祥, 张 佳等. 苦草 (Vallisneria natans) 根系对沉积物中各形态磷的影响. 环境科学, 2014,35 (4): 1304-1310.

[13] 马久远, 王国祥, 李振国等. 太湖两种水生植物群落对沉积物中氮素的影响. 环境科学, 2013,34(11):4240-4250.

[14] 王立志, 王国祥, 俞振飞等. 沉水植物生长期对沉积物和上覆水之间磷迁移的影响. 环境科学, 2012, 33(2): 385-392.

[15] 王立志, 王国祥, 俞振飞等. 苦草(Vallisneria natans) 生长期对沉积物磷形态及迁移的影响. 湖泊科学, 2011, 23(5): 753-760.

[16] 俞振飞, 王国祥, 王立志等. 苦草 (Vallisneria natans) 和黑藻 (Hydrilla verticillata) 对沉积物各形态磷垂直分布的影 响. 湖泊科学, $2012, \mathbf{2 4}(3): 378-383$.

[17] 中国科学院《中国植物志》编委会. 中国植物志. 北京:科学出版社,1999.

[18 ] Ralph P, Gademann R, Dennison W. In situ seagrass photosynthesis measured using a submersible, pulse-amplitude modulated fluorometer. Marine Biology, 1998, 132(3) :367-373.

[19] 李 强,王国祥, 潘国权等. 水体浊度对菹草萌发及萌发苗光合苂光特性的影响. 生态学报, 2006, 26(11): 3594-3601.

[20] Ralph PJ, Gademann R. Rapid light curves : a powerful tool to assess photosynthetic activity. Aquatic Botany, 2005,82 (3) :222-237.

[21] Schreiber U, Gademann R, Ralph P et al. Assessment of photosynthetic performance of Prochloron in Lissoclinum patella in hospite by chlorophyll fluorescence measurements. Plant and Cell Physiology, 1997, 38( 8 ) :945-951.

[22] 张守仁. 叶绿素苂光动力学参数的意义及讨论. 植物学通报,1999,16 (4) :444-448.

[23] Demmig B, Björkman O. Comparison of the effect of excessive light on chlorophyll fluorescence and photon yield of $\mathrm{O}_{2}$ evolution in leaves of higher plants. Planta, 1987, 171(2):171-184.

[24] Wang B, Li W. Physiological reactions of Potamogeton malaianus to different N and P concentrations in the growth medium. Acta Ecologica Sinica, 2001, 22(10):1616-1621.

[25] 惠红霞, 许 兴, 李前荣. 外源甜菜碱对盐胁迫下枸杞光合功能的改善. 西北植物学报,2003,23(12):2137-2142.

[26] 韩博平,韩志国, 付 翔. 藻类光合作用机理与模型. 北京:科学出版社, 2003 .

[27] 宋玉芝, 蔡 炜, 秦伯强. 太湖常见浮叶植物和沉水植物的光合苂光特性比较. 应用生态学报, 2009, 20(3): 569-573.

[28] Dawson S, Dennison W. Effects of ultraviolet and photosynthetically active radiation on five seagrass species. Marine Biology, 1996, 125 (4) : 629-638. 